J. Clin. Chem. Clin. Biochem.

Vol. 26, 1988, pp. $201-208$

(C) 1988 Walter de Gruyter \& Co. Berlin - New York

\title{
Physicochemical Determinations of Glucose in vivo
}

\author{
By J. D. Kruse-Jarres \\ Institut für Klinische Chemie und Laboratoriumsmedizin, Katharinenhospital, Stuttgart
}

(Received September 21, 1987 / January 4, 1988)

Summary: Conventional methods for the determination of blood glucose are not suitable for application in vivo. It is therefore necessary to seek other methods for monitoring blood glucose as a controlled variable of pancreatic hormonal regulation. Physical methods are preferable to conventional chemical methods, because the chosen methods should not consume or chemically modify glucose. There are two main types of physical chemical methods, which can be considered for this purpose:

1) invasive methods, in which measurements are made directly in the blood stream, and

2) non-invasive methods.

The first type is represented by electrochemical catalysts and fuel cells, the latter by spectroscopic procedures (mainly NMR- and IR-spectroscopy).

\section{Introduction}

With respect to the dynamic state of body constituents, the human organism is an open system. In this context, the physiological and pathobiochemical regulation of blood glucose and its associated dynamic equilibria have always been of especial interest.

It is now possible to regulate blood glucose extracorporally, using insulin infusion controlled by a glucose monitoring system (known as the "artificial pancreas"). This permits the construction of individually programmed and computer-controlled regulatory devices. The operational reliability of such systems is relatively high, but a continuously operating, reliable and rapid method for determination of the circulating blood glucose concentration is still lacking. Further development of regulatory systems will depend on such a system.

Conventional wet chemical methods (e. g. hexokinase/ glucose-6-phosphate dehydrogenase, glucose dehydrogenase or glucose oxidase/peroxidase methods) $(1-5)$ cannot be used in vivo, because substrateconsuming methods are not applicable inside the organism. Extracorporal determination of glucose via a double lumen catheter with the aid of continual re- cording can only be a temporary arrangement for a limited time period. It suffers from the disadvantages of all invasive methods, i.e. a relatively high consumption of blood and damage to the vein wall with all its attendant complications (tissue reaction, fibrin layer formation, deposition of protein, thromboses, etc.) (6).

This restriction on the application of conventional methods for the determination of blood glucose makes it necessary to seek methods, which do not consume or chemically modify glucose, and which are sufficiently accurate to act as regulators for the hormonal control of blood glucose via the artificial pancreas. Conventional chemical methods must therefore be replaced by physical chemical methods.

There are two different physical principles of measurement:

1) invasive methods, in which measurements are made directly in the tissue or blood, and

2) non-invasive methods.

The first type is represented mainly by electrochemical catalysts, the latter by spectroscopic methods. Other procedures (e. g. polarimetry, optical rotation, measurement of the change of potential at cell membranes 
(condimetry), measurement of transcutaneous resistance, light scattering, etc.) have all been tested and found to be either too unspecific or too insensitive. They have occasionally been applied in daily clinical practice, but a satisfactory correlation of response and blood glucose concentration has not been shown for any of the named procedures.

\section{Invasive Procedures}

Electrochemical catalysts, also known as biosensors, have already been used for the development of implantable glucose sensors. The detector system may or may not contain an immobilized enzyme.

\subsection{Biosensors containing enzymes}

Principle

The best known of these procedures uses a polarographic sensor to measure the oxygen uptake during the oxidation of glucose in the presence of glucose oxidase. Measurement is performed with a platinum cathode (coated with glucose oxidase containing polyacrylamide) and a $\mathrm{Ag} / \mathrm{AgCl}$ anode in the electrolyte solution $(7-8)$.

The hydrogen peroxide electrode operates on a similar principle to that of the oxygen electrode. Oxidation of glucose in the presence of glucose oxidase produces gluconolactone and hydrogen peroxide. The latter is measured directly by an electrode (platinum anode, silver cathode; similar to the well known Clark electrode) after passing through selective membranes of various porosities, and the response is proportional to the glucose concentration.

\section{Evaluation}

The oxygen electrode enables a sufficiently exact, rapid and interference-free measurement of oxygen uptake, which is proportional to the glucose concentration. The method has been used in a continuous extracorporal analytical device (Biostator) $(9-10)$. On-line coupling of an oxygen electrode with a calculator and an insulin infusion pump represents an "artificial endocrine pancreas" (also called an "artificial $\beta$-cell").

The hydrogen peroxide electrode can be used for the extracorporal measurement of glucose in fluids, especially whole blood. This method has the advantage of low susceptibility to interference, since electrodeactive substances (e. g. ascorbic acid, glutathione, uric acid, cysteine) are excluded by the various membranes (11).

\subsection{Fuel cells (enzyme-free biosensors)}

\section{Principle}

The principle of this method was first described by Bessman \& Schultz (12). Glucose is oxidized anodically to gluconic acid with the aid of a noble metal electrode (platinum or gold), and 'oxygen reduction at the cathode is measured directly, the resulting diffusion current being proportional to the glucose concentration. The catalyst is regenerated by the application of continuous square wave pulses $(30 \mathrm{~V}, 20 \mathrm{~ms}$, $\left.5 \mathrm{~s}^{-1}\right)(13)$.

\section{Evaluation}

At present the noble metal electrode suffers from a lack of specificity. Other oxidizable substances, like amino acids and proteins, as well as urea and creatinine, give rise to an interfering anodic partial current density, for which there is no known remedy. These substances generate an electrode potential similar to that for glucose, and in the same potential range, so that the signals are superimposed.

Interpretation of these electrode currents in the voltagram is very difficult, and in principle it is not fully understood. Whether the electrochemical determination of glucose represents the registration of a catalytic process, or whether the reduction or oxidation of glucose is itself directly responsible for the electrode current, is an open question. In polarograms with a mercury dropping electrode, which permit quantitative measurement of oxidation and reduction processes by characteristic alterations of the current (polarographic steps), we detected no such changes, even at very high glucose concentrations. We must therefore conclude that the glucose-dependent increase of the electrode current as shown by Soeldner et al. (1419) cannot be explained by a simple redox reaction of glucose at the electrodes.

For the reasons stated, the functional efficiency of these electrodes is very limited when they are implanted in tissues, but they may be a little more suitable for use in blood $(29-23)$.

\section{Section summary}

Both of the above-mentioned invasive methods, the enzyme-based biosensors and the fuel cell, have been used in vivo with hitherto only very limited, shortterm success $(24-31)$. For extracorporal measurements, however, they have been applied to a variety of scientific and clinical problems, with notable results $(11,32-44)$. 


\section{Recent Advances in Steroid Hormone Action}

\section{Editor V.K. Moudgil}

1987. $17 \mathrm{~cm} \times 24 \mathrm{~cm}$. VII, 552 pages. Numerous illustrations. Hardcover. DM 270,-; approx. US \$ 159.00 ISBN 3110107627

Steroid hormones are involved in numerous complex physiological and developmental processes. During the past three years, there has been an explosion of new information on the structure and function of steroid receptors and their genes.

This book contains invited chapters contributed by leading scientists in the general area of molecular mechanism of steroid hormone action. The authors have applied new technology to closely examine facets of molecular organization of steroid regulation. The chapters in the book have been prepared to provide a reader with sufficient background, needed methodological details and discussion that is easy to comprehend.

\section{Contents (Main Chapters)}

Introduction - Cloning of Steroid Receptors and Gene Expression • Steroid Hormone Receptors: Structure and Modifications - Analysis of Steroid Receptors in Cancer Cells - Advances in Methodological Approaches · Author Index · Subject Index. 


\section{NEW, COMPLETELY REVISED THIRTEENTH EDITION ·}

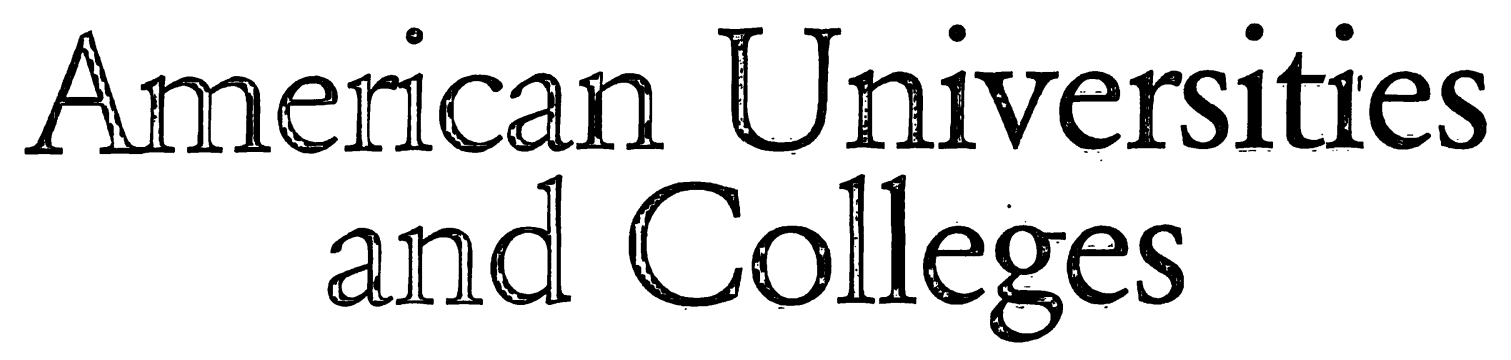

Produced in collaboration with the American Council on Education

1987. $21 \times 27.5 \mathrm{~cm}$. XX, 2040 pages. With numerous charts and tables.

Cloth DM298,- ISBN 3110109026

American Universities and Colleges is published every four years.

We invite standing orders.

Based on a new survey begun in September 1986, this completely updated and expanded edition of American Universities and Colleges continues the tradition of being the foremost reference book on postsecondary education in the United States. Prepared in collaboration with the American Council on Education, the major coordinating body of higher education, the revised Thirteenth Edition provides the most comprehensive collection of information on accredited institutions offering baccalaureate degrees and above.

The Thirteenth Edition is enlarged both in the number of institutions represented and the amount of information provided. Over 1,900 institutions are covered, including 125 new institutions recently accredited.

American Universities and Colleges provides both the essential statistical data (tuition, room, board, admissions requirements, financial aid, enrollments, etc.) and all the other information equally important to decision making (student life, library holdings, physical plant, accelerated and study-abroad programs, etc.). A full section is devoted to the foreign student in U.S. institutions. Included is a list of overseas offices with counseling services on study in the U.S., plus a number of tables dealing with various aspects of foreign student enrollments from $1954-55$ to $1985-86$.

Another section deals with professional education in the U.S., using nearly 40 subject areas to discuss the institutions offering professional programs, admission and degree requirements, and licensing and certification programs. Other sections deal with such diverse topics as the history of higher education in the U.S. and the academic costume code.

\section{From reviewes of the Truelfth Edition:}

"To sum up these five guides ... no high school, public, or academic library reference collection is adequate without AUC."

Choice

"The new edition continues the tradition of completeness... No other general purpose college guide offers similar coverage ... belongs in every academic, public, and high school library, for it provides perspectives on colleges other guides do not even consider."

Wilson Library Bulletin

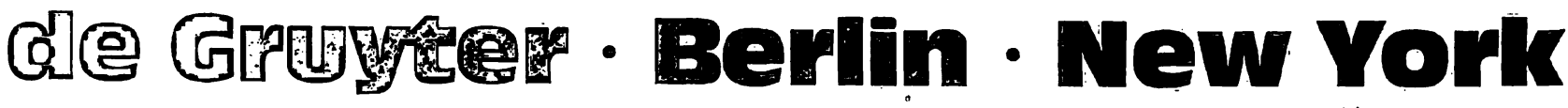




\subsection{Other biosensors}

In principle, any physical chemical method can be incorporated into a biosensors, provided it does not cause irreversible organ damage. Nevertheless, with respect to glucose measurement in vivo, the number of possible methods is minimal (45).

\section{Principle}

Piezoelectric crystals employ the electrically generated oscillations of quartz crystals, whose frequency is proportional to the mass of the crystal. Masses of $10^{-12} \mathrm{~g}$ can be determined in this way. The technique has been successfully applied to immunoassays.

Optical sensors (optodes) operate on a fluorimetric principle, using immobilized dehydrogenases. With the aid of multi-fibre optical conductors (fibre optics), they can be operated at some distance from the site of the measurement. They have been introduced successfully for both immunological and enzymological measurements.

FET biosensors (Field Effect Transistors) are signal transducers based on semiconductors. They are designed to respond to alterations in an established electrostatic field caused by the presence of molecules. Hitherto, this method has been applied only to pure, aqueous solutions, or to defined fluids, and not to body fluids. FET biosensors have proved to be highly efficient for the determination of the isoelectric points of antibodies, and are therefore employed as immune sensors.

Thermistors measure the temperature of exothermic reactions. With the aid of a flow-through microcalorimeter, they are able to detect very small temperature shifts during biological reactions, such as the enzymic conversion of a substrate.

\section{Evaluation}

Biosensors, which do not depend on the selective micro-electronic measurement of molecules (electrochemical voltammetry), as described in sections 1.2 and 1.3, unfortunately have no or very limited application in vivo. Piezo-crystals promise to become an interesting detection system for the determination of enzymes and antibodies, but they appear to be unsuitable for the determination of glucose. The use of optical sensors for the determination of glucose in vivo is not yet possible. A specific effect of glucose on the conductivity of transistors has not yet been demonstrated, so that this type of in vivo method is out of the question. Thermistors show outstanding sensitivity in the measurement of glucose (down to $0.002 \mathrm{mmol} / \mathrm{l}$ ), but this applies only to aqueous solutions; the use of thermistors for the in vivo measurement of glucose is inconceivable.

\section{Section summary}

On the basis of our present knowledge and the state of technical development, the application of any other electronic analytical principle as a biosensor for the invasive determination of blood glucose in vivo seems to be out of the question. On the one hand, it may be worthwhile devoting time to the construction of membrane-covered cathodes with the highest possible specific permeability and stable sensitivity. On the other hand, this positive aspect is offset by the aggravating susceptibility to interference of catalytic biosensors. Furthermore, in order to avoid the problem of indirect determination by measurement of the reaction product, it is necessary to seek possible methods of measuring glucose concentration without consumption or modification of the molecule.

\section{Non-invasive Methods}

Since there is little prospect for the successful application of invasive methods, it is necessary to consider non-invasive, spectroscopic methods for monitoring blood glucose in vivo. The practical application of the methods in question is, however, far from realization, and the necessary technology crosses many disciplinary boundaries. Only spectroscopic methods appear to be suitable for the purpose. These are widely used routine methods of physics and analytical chemistry, which have not yet been fully exploited in medicine. Moreover, their specialized application in vivo is dependent on the solution of many hitherto unsolved problems. In this respect, only a few of the various spectroscopic methods appear to be suitable for coping with the problems of non-invasive monitoring in vivo. For example, $\mathrm{X}$-ray spectroscopy is excluded, since it would cause cellular damage and gene mutation.

\subsection{Nuclear magnetic resonance (NMR)}

\section{Principle}

Nuclear magnetic resonance (NMR) is one of the more promising non-invasive methods. It depends on the fact that most atomic nucleic have a characteristic spin, and therefore possess a magnetic moment (46). In an homogeneous, static magnetic field, the vector of the spin is quantized, so that each orientation of spin relative to the magnetic field corresponds to a 
discrete energy level. Occupation of these energy levels shows a Boltzmann distribution, and magnetic resonance absorptions correspond to transitions between the energy levels, i.e. irradiation energy is absorbed in quanta, which represent the differences between energy levels. The area under an absorption curve is a measure of the intensity of the transition, and this in turn is proportional to the number of absorbing nuclei. The NMR spectrum of a finger in a magnetic field would therefore contain spectroscopic information about glucose.

\section{Evaluation}

Techniques of signal filtering and subtraction have raised NMR from a Utopian idea to the status of a practical technique capable of providing quantitative information on substrate concentrations in vitro and in vivo. The requirement for a rather large magnet and a radiofrequency transmission and receiving system means, however, that the method is still very costly and large-scale. The advantage, however, is that the excitation and response of the investigated atomic nuclei occur in the form of low frequency electromagnetic radiation. This means that the circulating concentration of glucose, as well as those of a large number of other clinical chemical parameters in blood (47), can be measured rapidly, with avoidance of bodily contact, and without having to consider optical, mechanical or electrical interference (48). Since no reagents are used, economic considerations will lead to the elevation of this type of analysis to an important position in future laboratory medicine, and it can be expected to change the face of conventional clinical chemical analysis.

Although NMR has been used satisfactorily for the determination of ATP in vivo in various organs (49), there is a considerable obstacle to its use for the determination of glucose in vivo; the relevant carbon nucleus for the determination of glucose possesses a relatively low signal intensity compared with the natural nuclides ${ }^{1} \mathrm{H},{ }^{15} \mathrm{~N},{ }^{31} \mathrm{P}$ and ${ }^{13} \mathrm{C}$. In this respect, it would be much easier to determine the metabolically active glucose 6-phosphate.

\subsection{Electron spin resonance (ESR)}

Principle

Electron spin resonance might conceivably be applied in the same way as NMR spectroscopy for the determination of glucose in vivo. In a magnetic field the parameters of electron spin behave analogously to those of nuclear spin.

\section{Evaluation}

In research, ESR is being increasingly used for the observation of intracellular metabolic processes and membrane behaviour $(50-56)$. No detailed studies have been reported, however, on the use of ESR for the determination of glucose. .,

\subsection{Positron emission tomography (PET)}

\section{Principle}

In the PET method, radioactive nuclides are injected, which emit positrons (positively charged anti-electrons) when they decay. The positrons interact with the electrons of neighbouring molecules to produce two mono-energetic gamma rays, which are emitted in opposite directions, and can therefore be measured with two separate detectors (57). Thus measurements are based on a spatial relationship.

\section{Evaluation}

At present, this non-invasive method for monitoring metabolic processor after incorporation of radioactive materials $\left({ }^{11} \mathrm{C},{ }^{13} \mathrm{~N}\right.$, etc.) is still at the forefront of research (58). In a few years time, however, this type of functional diagnosis on the molecular level could revolutionize laboratory diagnosis. It does not depend on the random determination of individual parameters in a static situation, but rather provides information on biodynamic processes, permitting the interpretation of specific metabolic events (59).

In addition to locating the sites of active metabolism, this method also enables the surveillance of e. g. blood flow and perfusion measurements, and can thus provide an important biochemical basis for the diagnosis of molecular function. The method therefore achieves more than the measurement of blood glucose; it measures glucose turnover in the tissues, thereby directly providing information on this biologically and clinically relevant process.

\subsection{Infrared spectroscopy (IR)}

Currently, the most promising method for the noninvasive determination of blood glucose is infrared spectroscopy (IR).

\section{Principle}

Molecules with a permanent dipole moment or molecules with a variable dipole absorb energy of the electromagnetic spectrum in or near to the infrared. The resulting absorption bands can be assigned to 
specific structural elements. Infrared spectroscopy measures the electromagnetic radiation energy (wave number $4000-600 \mathrm{~cm}^{-1}$ ) absorbed by the oscillation and rotation of functional groups. Absorption of radiation by any molecule occurs only at certain discrete energy levels, which are characteristic of that molecule. These energies vary, depending on the arrangement of atoms in the molecule. IR spectroscopy is therefore a relatively simple, rapid and reliable technique for the chemical identification of molecules or their structural groups $(60-63)$.

Thanks to rapid developments in the field of small, high performance computers, the quantitative evaluation of the discrete bands of the infrared spectrum presents no problem. Programs are available (e.g. least-squares-curve-fitting with Quant-3), which handle the mathematically demanding analysis of multicomponent systems with overlapping bands.

For the application of this technique to glucose monitoring in vivo, it must be possible to use the recorded spectrum directly. This requires processing of the signal so that the spectrum is directly related to concentration, involving the addition of spectra (spectral accumulation for the improvement of signal to noise ratio), and the intensification of spectra in binary steps. Understandably, this is only possible with expensive equipment. Modern FTIR (Fourier Transform Infra Red spectroscopy) apparatuses, employing Fourier transformation and a Multiplex facility, achieve a considerable energy gain, which can be exploited to decrease the time for registration of the spectrum, or to improve the signal to noise ratio (64). Complete computer back-up (e.g. multicomponent analysis by curve fitting, using the method of least squares) provides the following extra facilities and advantages:

a. Generation and further application of pure spectra, i. e. the spectrum of the dissolved species is produced by subtraction of the spectrum of the matrix.

b. Practically any desired substance concentration can be simulated by linear multiplication.

c. A spectral library can therefore be generated, then used to obtain a summated spectrum by multiple addition, which agrees as closely as possible with the sample spectrum. Furthermore, the composition of the sample can be determined by multiple subtraction of individual spectra from the sample spectrum.

d. Summation of many spectra to improve the signal to noise ratio offers a facility for measuring very low glucose concentrations in hypoglycaemia with sufficient accuracy. e. By linear combination of individual spectra, it should also be possible to simultaneously determine several other parameters in the sample.

\section{Evaluation}

The greatest source of interference in this method, which must first be overcome by modern analytical techniques, is the high background absorption due to water. With available light sources, it is not yet possible to obtain satisfactory results in the so-called water windows of the near infrared region at $1500-$ 1850 and $2000-2500 \mathrm{~nm}$. Since suitable laser diodes with good monochromatic output are also not yet available for these ranges, methods must be employed which record in the middle infrared region, with correction for interference.

A simple example of the results from a dispersive and relatively insensitive apparatus is given in figure 1.

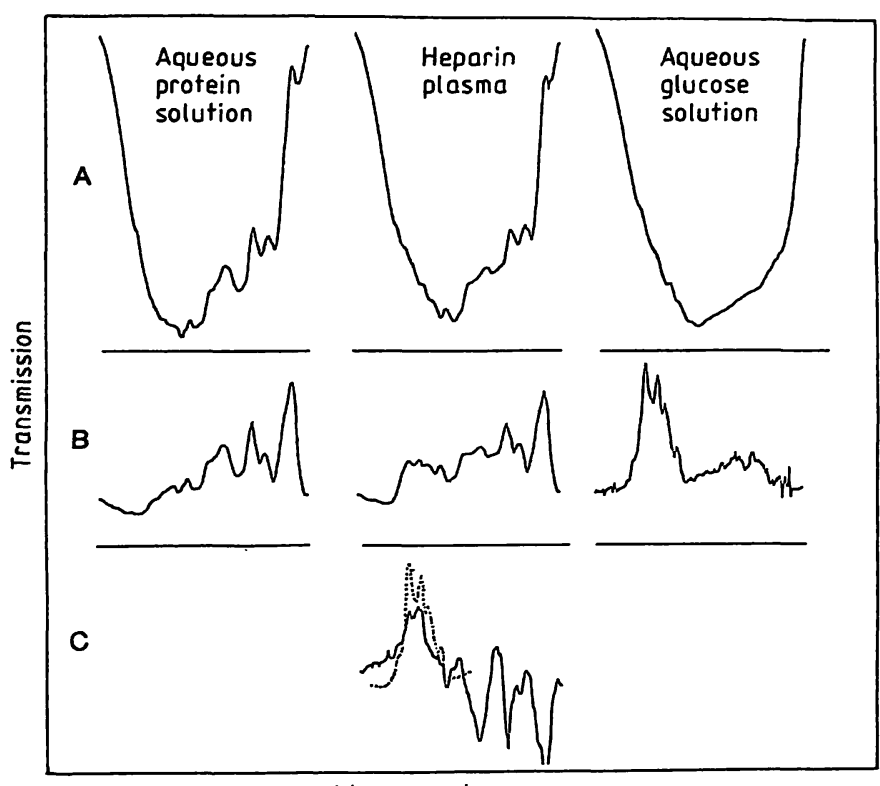

Wave number range

Fig. 1. IR-spectrum of human plasma without taking into account the subcutis and its constituent glycoproteins. A (top), original spectra. Left: aqueous protein solution ( $81 \mathrm{~g} / 1$ bovine serum albumin). Centre: heparin plasma (patient sample containing about $220 \mathrm{mg} / \mathrm{dl}$ glucose). Right: aqueous glucose solution $1000 \mathrm{mg} / \mathrm{dl}$ ). Wavenumber range 850 to $1600 \mathrm{~cm}^{-1}$, corresponding to 11750 to $6250 \mathrm{~nm}$ (barium fluoride window; sample layer about $26 \mathrm{~nm}$; transmission scale: upper edge of frame $100 \%$, lower edge about $18 \%$ transmission).

B (centre); spectra of the same dissolved substances after subtraction of the spectrum of the aqueous medium. It can be seen that the main components of plasma are proteins (right half of the difference spectrum).

C (bottom), difference spectrum of heparin plasma after subtraction of the spectrum of the aqueous protein (part A). The absorption bands of glucose can be seen, although they are partly covered. For easier identification, the bands of the glucose spectrum from part $B$ have been superimposed as a dotted line. 
The treatment of results shown in figure 1 is only suitable for the qualitative identification of the absorption bands, because each spectral subtraction leads to considerable deterioration of the signal to noise ratio. Multicomponent analysis without spectral subtraction is much more suitable for quantitative evaluation. The efficient presentation of difference spectra is only possible by electronic means.

Some exemplary reasons for the difficulties in the IRspectroscopic determination of glucose in any matrix from water to blood are as follows. Reference cuvettes are required for the measurements; experience shows that these can be a source of inaccuracy, due to the variable thickness of the layer, so that each cuvette must be individually tested before use. Long periods of measurement result in noticeable warming of the sample, so that the depth and concentration of the sample do not remain constant, leading to a significant decrease of accuracy. Since the spectra themselves cannot be altered, the final result is at best an approximation. For example, allowance must be made for the fact that the low water content of blood (compared with physiological saline) cannot be simulated. Intensification, i.e. expansion of difference spectra, is only an unsatisfactory provisional means of dealing with this problem.

These described procedures have been applied to EDTA-whole blood in vitro with encouraging results, which justifies the expectation that the quantitative

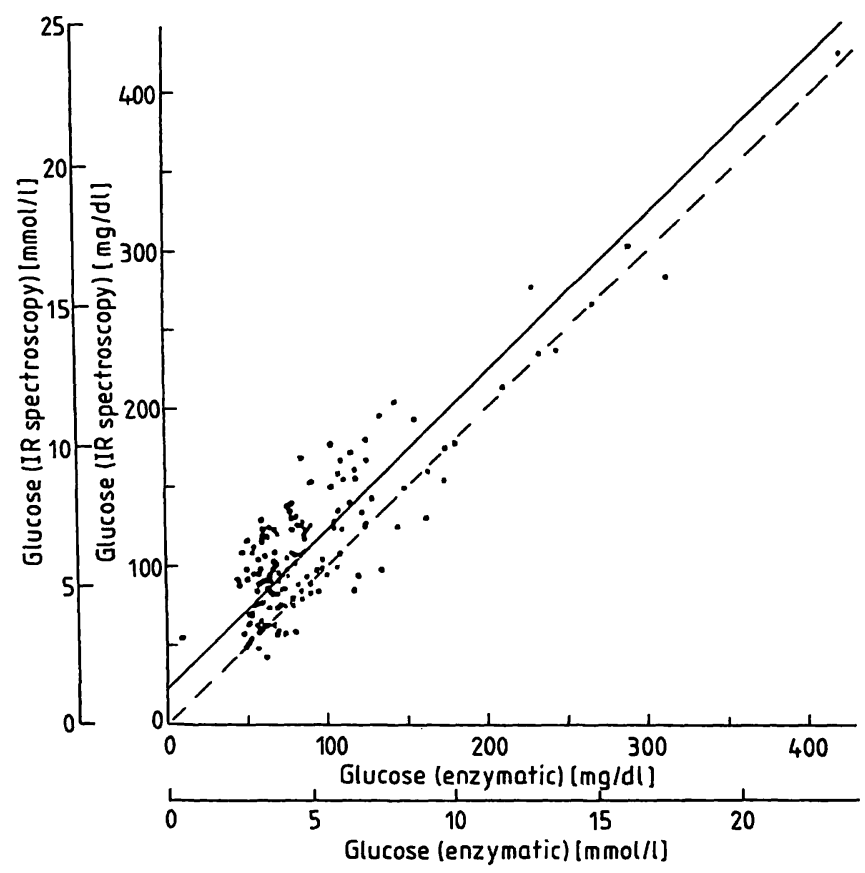

Fig. 2. Correlation between glucose determination in whole blood by IR-spectroscopy (ordinate) and enzymically with glucose dehydrogenase (abscissa). $\mathrm{N}=147$, $\mathrm{y}=22.27+1.01 \mathrm{x}, \mathrm{r}=0.863$
IR-spectroscopic determination of glucose will be achieved, first in vitro, and later in vivo. Comparison of glucose concentrations measured in this way with those determined by the conventional glucose dehydrogenase method shows a correlation coefficient ( $r$ ) of 0.80 (fig. 2). For the measurement of relevant hypoglycaemic glucose concentrations below 2.5 $\mathrm{mmol} / \mathrm{l}$, a further optimization of the specific signal evaluation is necessary for a guarantee of satisfactorily reproducible results.

\subsubsection{Infrared spectroscopy with a $\mathrm{CO}_{2}$ laser}

A convenional IR apparatus with a normal thermal light source, even with the extra facilities described above, is inadequate for the measurement of most IR-active blood constituents. This is largely due to the high background absorption resulting from the water. Thermal emitters produce insufficiently powerful absorption bands.

\section{Principle}

The development, in recent years, of laser techniques, has enabled the quantitative determination of biochemical substrates and metabolites, using high energy radiation sources. The combination of IR-spectroscopy with a $\mathrm{CO}_{2}$ laser has been considered for the determination of glucose. Of the presently available laser systems (e. g. Excimer, $\mathrm{Ar}+/ \mathrm{Kr}+, \mathrm{Nd} / \mathrm{YAG}$ and $\mathrm{CO}_{2}$ ) only the $\mathrm{CO}_{2}$ laser provides IR-emission at 1000 $\mathrm{nm}$, which is required for glucose measurement.

\section{Evaluation}

Compared with thermal light sources, lasers have the advantage of greater coherence (optimal spatial and temporal co-ordination), better collimation (lower divergence) and higher spectral intensity (monochromicity) (65). Introduction of this type of laser for the spectroscopic determination will certainly enable a precise measurement of glucose, even below 2.5 $\mathrm{mmol} / \mathrm{l}$, and provide a sound basis for the continuous determination of the actual concentration of circulating blood glucose in vivo.

\subsubsection{Infrared spectroscopy with ATR prisms}

Kaiser (66) made the interesting suggestion of measuring the physiological concentration of glucose in very thin layers by using ATR ( $A$ ttenuated Total Reflection) prisms; this was intended to overcome the problems of measurement in blood vessels or in well vascularized tissues (ear lobes, lips, mucosa), without the need to release blood. 


\section{Principle}

The phenomenon of total reflection is characterized by the fact that reflected light energy at the boundary layer of two media is capable of providing information on the absorption of radiation by the optically denser medium. Energy is not transferred from the optically denser to the optically less dense medium. The electromagnetic field, however, spreads outwards in a narrow boundary layer to the optically denser medium. If the less dense medium is not transparent, the equilibrium between incident and reflected light is disturbed by radiation absorption in the boundary layer. This attenuated total reflection can be exploited for spectrosocopic purposes.

\section{Evaluation}

The potential of this method was first assessed in the studies of Kaiser (66-68). Replacement of transmission measurement by an ATR prism has the advantages of the absence of dependence on the cuvette light path, the extremely small accompanying temperature difference, and the increase of sensitivity (69) resulting from multiple reflection and the associated large volume of analysed material.

\subsection{Raman spectroscopy}

\section{Principle}

Raman spectroscopy measures both the normal absorption and the scatter of incident monochromatic light. In addition to the intense line of the excitation frequency, there are additional, very weak Raman lines with shifted frequencies. These represent oscillation and rotation frequencies of molecules as they absorb or release energy. During the measurement of the absorption of incident radiation, these resonance attenuations or intensifications lead to shifts of spontaneous fluorescence, which provide information about changes in the energetic state, and moreover the quantity of the molecules under investigation $(70-71)$.

\section{Evaluation}

The useful Raman spectra of glucose lie in the range $500-1000 \mathrm{~cm}^{-1}$. So far, however, satisfactory results have only been obtained for aqueous solutions, due to the fact that whole blood contains many other chromophoric substances absorbing in this region. These other blood constituents are responsible for an intense background fluorescence, which renders impossible the identification of specific resonance-intensified bands. It has not yet been possible to obtain satisfactory results, even with laser sources. Moreover, the accompanying technology is expensive. Electronic background subtraction may subsequently improve the usefulness of the technique for quantitative purpose, but at the moment the desirable is separated from reality by a Utopian divide (72).

\section{Conclusions}

For the observation and measurement of the dynamic state of metabolic processes, it is necessary to move away from traditional, in vitro investigations of single parameters in random samples of body fluids (usually blood) in favour of continuous and, as far as possible, non-invasive methods. Invasive methods (biosensors) have so far failed to perform adequately, and they have the additional drawback of damage to the skin and tissues, with the attendant consequences (infection, thrombosis, granuloma). The practical potential of non-invasive spectroscopic methods is evident from a certain level of success in their experimental application, but their clinical application will depend on further progress at the research front. In particular, infrared spectroscopy linked to new techniques (laser sources, reflection measurement, Fourier transformation, computer back-up) offers the greatest hope for further progress.

\section{Acknowledgements}

I acknowledge the very conscientious investigations of my collaborator, Dr. rer. nat. Günter Janatsch, at the Katharinenhospital. We are grateful to the civic authorities of Stuttgart for experimental equipment, and to the Breuninger Foundation and the Landesgirobank (State Savings Bank) Stuttgart for financial support. I am endebted to Prof. Günther Tölg, Institut für Spektrochemie und Angewandte Spektroskopie Dortmund, and Prof. Johann Weidlein, Institut für Anorganische Chemie der Universität Stuttgart, for their help and for their stimulating and critical discussions.

\section{References}

1. Banauch, D. (1975) Z. Klin. Chem. Klin. Biochem. 13, $101-107$

2. Hugget, A. S. G. \& Nixon, D. A. (1957) Lancet II, 368.

3. Hugget, A. S. G. \& Nixon, D. A. (1957) Biochem. J. 66, 12.

4. Schmidt, F. H. (1961) Klin. Wochenschr. 39, 1244-1247.

5. Slein, M. W., Cori, G. T. \& Cori, C. F. (1950) J. Biol. Chem. 186, 763.

6. Woodward, S. C. (1982) Diabetes Care 5, 278-281.

7. Clark, L. C. \& Lyons, C. (1962) Ann. N. Y. Acad. Sci. 102, $29-46$.

8. Updike, J. W. \& Hicks, J. P. (1967) Nature 214, 986-988. 
9. Clemens, A. H., Chang, P. H. \& Myers, R. W. (1976) J. Ann. Diabétol. Hôtel 1976, 269-278.

10. Clemens, A. H., Chang, P. H. \& Myers, R. W. (1977) Horm. Metab. Res. Suppl. 8, 23-33.

11. Williams, G., Pickup, J., Clarke, A., Bowcock, S., Cooke, E. \& Keen, H. (1983) Diabetes 32, 466-473.

12. Bessman, S. P. \& Schultz, R. D. (1972) Horm. Metab. Res. 4, 413-417.

13. Chang, K. W., Aisenberg, S., Soeldner, J. S. \& Hiebert, J. M. (1973) Trans. Amer. Soc. Artif. Organs 19, 352-360.

14. Soeldner, J. S., Chang, K. W., Aisenberg, S. \& Hiebert, J. M. (1973) Progress towards and implantable glucose sensor and an artificial beta cell. In: "Temporal aspects of therapeutics" (Urquhart, J. \& Yates, F. E., eds.) Plenum Press, New York, pp. 81-207.

15. Gough, D. A., Anderson, F. L., Giner, J., Colton, D. K. \& Soeldner, J. S. (1978) Anal. Chem. 50, 941-943.

16. Guyton, J. R., Soeldner, J. S., Giner, J., Colton, C. K. \& Morris, R. S. (1979) Horm. Metab. Res. Suppl. 8, 24-26.

17. Lerner, H., Giner, J., Soeldner, J. S. \& Colton, C. K. (1979) J. Electrochem. Soc. 126, 237-242.

18. Marincic, L., Soeldner, J. S., Giner, J., Colton, C. K. \& Morris, S. (1979) J. Electrochem. Soc. 126, 43-49.

19. Marincic, L., Soeldner, J. S., Giner, J. \& Colton, D. K. (1979) J. Electrochem. Soc. 126, 1687-1692.

20. Gough, D. A., Soeldner, J. S., Colton, S., Aisenberg, S. \& Giner, J. (1977) Horm. Metab. Res. Suppl. 7, 10-22.

21. Gebhardt, U., Luft, G., Richter, G. \& von Sturm, F. (1977) Biomed. Techn. 22, 399.

22. Soeldner, J. S. (1981) Am. J. Med. 70, 183-194.

23. Richter, G. J., Luft, G. \& Gebhardt, U. (1982) Diabetes Care 5, 224-228.

24. Buchwald, H., Barbosa, R. L., Varco, R. L., Rohde, T. D., Rupp, W. M., Schwartz, R. A. \& Goldsberg, F. J. (1981) Lancet $I, 1233-1235$.

25. Clark, L. C. \& Duggan, C. A. (1982) Diabetes Care 5 , 174-180.

26. Kondo, T., Ito, K., Ohkura, K., Ito, K. \& Ikeda, S. (1982), Diabetes Care 5, 218-221.

27. Schade, D. S., Eaton, R. P., Edwards, W. S., Doberneck, R. C., Spencer, W. J., Carlson, G. A., Bair, R. E., Lowe, J. T., Urenda, R. S. \& Gaona, J. I. (1982) J. Am. Med. Soc. $247,1848-1853$.

28. Shichiri, M., Kawamori, R., Yamasaki, Y., Hakui, N. \& Abe, H. (1982) Lancet $I I, 1129-1131$.

29. Shichiri, M., Kawamori, R., Goriya, Y., Yamasaki, Y., Nomura, M., Hakui, N. \& Abe, H. (1983) Diabetologia 24, 179-184.

30. Wilkins, E. \& Wilkins, M. G. (1983) J. Biomed. Eng. 5, $309-315$.

31. Wolfson, S. K., Tokarsky, J. F. \& Krupper, M. A. (1982) Diabetes Care 5, 162-165.

32. Albisser, A. M., Leibel, B. S., Ewart, T., Davidovac, Z. \& Zingg, W. (1973) Diabetes 22, Suppl. 1, 294.

33. Pfeiffer, E. F., Thum, Ch. \& Clemens, A. H. (1974) Horm. Metab. Res. 6, 339-342.

34. Layne, E. C., Schultz, R. D., Thomas, L. J., Slama, G., Sayler, D. F. \& Bessman, S. P. (1976) Diabetes 25, 81-89.

35. Kruse-Jarres, J. D. \& Molnar, G. D. (Ed.) (1977) Horm. Metab. Res. Suppl. 7, 2-157.

36. Fogt, E. J., Dodd, L. M., Jenning, E. M. \& Clemens, A. H. (1978) Clin. Chem. 24, 1366-1372.

37. Santiago, J. V., Clemens, A. H., Clarke, W. L. \& Kipris, D. M. (1979) Diabetes 28, 71-84.

38. Pickup, J. C., Keen, H., Viberti, G. C., White, M. C., Kohner, E. M., Parsons, J. A. \& Alberti, K. G. M. M. (1980) Diabetes Care 3, 290-300.
39. Nosadini, R., Noy, G., Nattrass, M., Alberti, K. G. M. M., Johnston, D. G., Home, P. D. \& Orskov, H. (1982) Diabetologia 23, 220-228.

40. Schultz, J. S., Mansouri, S. \& Goldstein, I. J. (1982) Diabetes Care 5, 245-253.

41. Wingard, L. B., Schiller, J. G., Wolfson, S. K., Liu, C. C., Drash, A. L. \& Yao, S. J. (1979) J. Biomed. Mater. Res. 13, 921-935.

42. Wingard, L. B. (1983) Fed. Proc. 4d, 288-291.

43. Wingard, L. B., Cantin, L. A. \& Castner, J. F. (1983) Biochim. Biophys. Acta 748, $21-27$.

44. Turner, A. P. F. \& Pickup, J. C. (1985) Biosensors 1, 85115.

45. Owen, V. M. (1985) Ann. Clin. Biochem. 22, 559-564.

46. Petersen, S. B., Rinck, P. A. \& Muller, R. N. (1986) Das Magnetresonanzphänomen, In: Magnetresonanz-Imaging und -Spektroskopie in der Medizin (Rinck, P. A., Petersen, S. B. \& Muller, R. N., eds.) Thieme Verlag Stuttgart, pp. $2-10$.

47. Brown, C. E., Battocletti, J. H. \& Johnson, L. F. (1984) Clin. Chem. 30, 606-618.

48. Holz, M. (1986) Nachr. Chem. Tech. Lab. 34, 858-864.

49. Gadian, D. G. (1986) Grundlagen und Instrumentierung der metabolischen Magnetresonanz. In: "MagnetresonanzImaging und -Spektroskopie in der Medizin" (Rinck, P. A., Petersen, S. B. \& Muller, R. N., eds.) G. Thieme Verlag Stuttgart, pp. 179-185.

50. Thomas, D. D. (1987) Ann. Rev. Physiol. 49, 691-709.

51. Crowder, M. S. \& Cooke, R. (1987) Biophys. J. 51, 323333.

52. Yang, A. S. \& Gaffney, B. J. (1987) Biophys. J. 51, 55-67.

53. Brill, A. S., Fiamingo, F. G., Hampton, D. A. (1986) J. Inorg. Biochem. 28, 137-143.

54. Lee, Y. H., Currie, B. L. \& Johṇson, M. E. (1986) Biochemistry $25,5647-5654$.

55. Davis, J. H. (1986) Chem. Phys. Lipids 40, 223-258.

56. Beth, A. H., Conturo, T. E., Venkataramu, S. D. \& Staros, J. V. (1986) Biochemistry 25, 3824-3832.

57. Ter-Pogossian, M. M. (1985) J. Necl. Med. 26, 1387-1498.

58. Weinreich, R. (1986) Swiss. Med. 8, 53-68.

59. Wagner, H. N. (1985) J. Nucl. Med. 26, 679-686.

60. Williams, D. H. \& Fleming, I. (1971) Spektroskopische Methoden in der organischen Chemie, 2. Aufl., Thieme Verlag Stuttgart, pp. 41-80.

61. Wilks, P. A. (1979) Internat. Lab. 1979, 49-58.

62. Alvarez, J., Lee, D. C., Baldwin, S. A. \& Chapman, D. (1987) J. Biol. Chem. 262, 3502-3509.

63. Susi, H. \& Byler, D. M. (1986) Methods Enzymol. 130, $290-311$.

64. Oelichmann, J. \& Rau, A. (1986) LaborPraxis 86, 638646.

65. Müller, G. J., Berlien, B. \& Scholz, C. (1986) Umschau 86, $233-240$.

66. Kaiser, N. (1975) Biomed. Techn. 20, 291.

67. Kaiser, N. (1977) Horm. Metab. Res. Suppl. 8, 30-33.

68. Kaiser, N. (1979) IEEE Trans. Biomed. Eng. BME 26, $597-600$.

69. Bauer, B. \& Floyd, T. A. (1987) Analyt. Chim. Acta 197, 295-301.

70. Asher, I. M., Carew, E. B. \& Stanley, H. E. (1976) Laser Raman spectroscopy: A new probe of the molecular conformations of intact muscle and its components. In: "Physiology of Smooth Muscle" (Bülbring, E. \& Shuba, M. F., eds.) Raven Press New York, pp. 229-238.

71. Yu, N.-T. (1977) CRC Crit. Rev. Biochem. 4, 229-280.

72. Brauner, H. \& Müller, G. (1980) Biomed. Techn. 25, $26-32$.

Prof. Dr. med. J. D. Kruse-Jarres

Institut für Klinische Chemie

und Laboratoriumsmedizin

Katharinenhospital Stuttgart

Kriegsbergstraße 60

D-7000 Stuttgart 1 